OPEN ACCESS

Edited by:

Jamie Peters,

University of Colorado, United States

Reviewed by:

Karen K. Szumlinski,

University of California,

Santa Barbara, United States

Abdeslam Chagraoui,

Université de Rouen, France

${ }^{*}$ Correspondence:

Gang Pang

panggang1975@aliyun.com

tThese authors have contributed equally to this work and share first authorship

Specialty section:

This article was submitted to

Motivation and Reward,

a section of the journal

Frontiers in Behavioral Neuroscience

Received: 18 October 2021 Accepted: 27 December 2021

Published: 09 February 2022

Citation:

Li B, Jiang J, Zhou L, Tao X, Sun Q, Liu J, Liu Y and Pang G (2022)

Blockade of 5-Hydroxytryptamine $2 \mathrm{~A}$ Receptor Attenuates Precipitation of Naloxone-Induced Withdrawal

Symptoms in Opioid-Exposed Mice. Front. Behav. Neurosci. 15:797217. doi: 10.3389/fnbeh.2021.797217

\section{Blockade of 5-Hydroxytryptamine 2A Receptor Attenuates Precipitation of Naloxone-Induced Withdrawal Symptoms in Opioid-Exposed Mice}

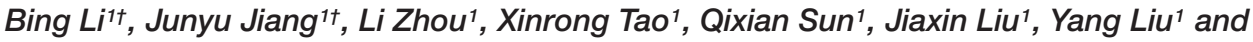 \\ Gang Pang ${ }^{2 *}$ \\ ${ }^{1}$ Center for Medical Research, School of Medicine, Anhui University of Science and Technology, Huainan, China, ${ }^{2}$ College \\ of Basic Medical Sciences, Anhui Medical University, Hefei, China
}

Heroin dependency has become a global problem and has caused significant clinical and socioeconomic burdens along with devastating medical consequences. Chronic drug exposure alters the expression and functional activity of 5-hydroxytryptamine (serotonin) 2A receptors (5-HT2ARs) in the brain. Furthermore, pharmacological blockade of 5-HT2ARs reduces cue-induced cocaine craving behaviors. In this study, we explored the influence of 5-HT2ARs on heroin-withdrawal behaviors in mice. Black C57BL/6J mice were given gradually increasing (10-50 mg/kg over 4.5 days) doses of heroin to induce heroin dependency, after which naloxone was given to precipitate withdrawal symptoms. MDL100907, a selective and potent 5-HT2AR antagonist, attenuated naloxone-precipitated withdrawal symptoms in these mice. In addition, 5-HT2AR protein levels increased significantly in the medial prefrontal cortex (mPFC), while phosphorylation of extracellular signal-regulated kinase ( $p$-ERK) decreased in the mPFC after heroin exposure. In conclusion, these results suggest that 5-HT2ARs might be involved in the development of opioid dependency and that pharmacological blocking of 5-HT2ARs might be a new therapeutic strategy for heroin dependency.

Keywords: addiction, serotonin, 5-HT2A R, MDL100907, heroin, withdrawal, hippocampus

\section{INTRODUCTION}

Diacetylmorphine (heroin) is one of the most addictive drugs. Heroin use disorders have become a global problem and have caused significant clinical and socioeconomic burdens along with devastating medical consequences. As a morphine derivative, heroin has a high-addictive potency. Once it enters the brain, heroin is rapidly hydrolyzed to 6-acetylmorphine and morphine by serum cholinesterase, which then binds with opioid receptors to activate dopaminergic neurons (Inturrisi et al., 1983; Johnson and North, 1992). Heroin derivatives have a high affinity for opioid receptors in the brain. The opioid receptor superfamily consists of $\delta$ (delta), $\kappa$ (kappa), and $\mu$ (mu) opioid receptors (DOR, KOR, and MOR, respectively) (Granier et al., 2012). MOR is hyperactivated after drug binding and modulates neurotransmitter efflux to reinforce addictive behaviors (Kreek et al., 2012).

Heroin addiction is increasing, especially in adolescents and young adults (Kuehn, 2013; Dart et al., 2015; Griesler et al., 2019; Kelley-Quon et al., 2019). Rehabilitation following heroin addiction 
takes a long time, and antidrug treatment can cause serious side effects in patients. Furthermore, deaths related to heroin overdose have been increasing at an alarming rate in the United States and Canada (Jalal et al., 2018; Banerjee et al., 2019; Dong et al., 2019; Jones et al., 2020). Heroin use can also cause longterm health complications, such as viral infections (Reardon, 2019), chronic obstructive pulmonary disease (Grischott et al., 2019; Tashkin, 2019; Nightingale et al., 2020), and cerebellar dysfunctions (Moreno-Rius, 2019).

Heroin disrupts the physiological neurotransmitter signaling cascades, especially those involving 5-hydroxytryptamine (5-HT) neurotransmitters. The 5-HT receptors modulate drug-addictive behaviors. For example, activation of 5-HT 2C receptors (5-HT2CRs) inhibits behavioral sensitization and drug dependency in heroin-treated mice ( $\mathrm{Wu}$ et al., 2015; Zhang et al., 2016). 5-Hydroxytryptamine (serotonin) 2A receptors (5-HT2ARs) also participate in opiate addiction in rodents and humans. Recently, Odagaki et al. (2021a,b) reported that long-term exposure to heroin leads to adaptive changes in 5-HT2ARs in the human brain. 5-HT2ARs activate phospholipase $\mathrm{C}$ through $\mathrm{G} \alpha_{\mathrm{q} / 11}$, which contributes to inositol 1,4,5-triphosphate and 1,2-diacylglycerol accumulation, intracellular $\mathrm{Ca}^{2+}$ release, and protein kinase $\mathrm{C}$ activation (Odagaki et al., 2021a,b).

5-Hydroxytryptamine (serotonin) 2A receptors regulate neuropsychological functions (Pogorelov et al., 2017; Mora et al., 2018; Odabas-Geldiay et al., 2019) and have been shown to play a role in a number of neurological disorders, including Alzheimer's disease (Ballard et al., 2018), Parkinson's disease (Cummings et al., 2014; Ohno et al., 2015), obsessive-compulsive disorder (El Mansari and Blier, 2006; Steeves and Fox, 2008; Simpson et al., 2011; Sinopoli et al., 2017), schizophrenia (Girgis et al., 2020), autism spectrum disorder (Chen et al., 2013), depression (Underwood et al., 2018), anxiety (Weisstaub et al., 2006), insomnia (Teegarden et al., 2008), and obesity (Morris, 2017). The 5-HT2AR antagonist volinanserin or MDL100907 (Aventis Pharmaceuticals) has been used to treat neuropsychological dysfunctions in drug-addicted patients (Cunningham et al., 2013), and a synergism between the 5-HT2AR and 5-HT2CR affects the severity of addictive behaviors (Cunningham et al., 2013; Perez-Aguilar et al., 2014; Prabhakaran et al., 2015; Felsing et al., 2018). 5-HT2ARs are ubiquitously expressed in all brain regions, with the highest receptor densities in the frontal and motor cortices (Price et al., 2019). The dorsomedial prefrontal cortex (PFC), specifically the prelimbic cortical region, plays a pivotal role in drug addiction reinforcement behaviors in rodents (Gourley and Taylor, 2016). Overexpression of 5HT2ARs has been associated with chronic dependency on opioids, worsening withdrawal symptoms, and relapse behavior after heroin exposure. These effects may have been mediated by downregulation of ERK/mitogen-activated protein kinase signaling in the PFC (Pang et al., 2016).

In this study, we aimed to investigate the impacts of 5HT2AR antagonists on heroin-withdrawal symptoms in mice. We showed that the selective 5-HT2AR antagonist, MDL100907 (volinanserin), significantly inhibits heroin-induced abnormal motor activities and withdrawal behavior in male mice.

\section{MATERIALS AND METHODS}

\section{Animals}

Male C57BL/6J adult mice, aged 8-12 weeks old [license \# SCXY (Su) 2011-0003] and weighing $20 \pm 2 \mathrm{~g}$, were purchased from Cavion (Cavion Experimental Animal Co., Changzhou, China). Mice were housed in groups of four in $29 \mathrm{~cm} \times 18 \mathrm{~cm} \times 12 \mathrm{~cm}$ polycarbonate cages with ad libitum access to water and food under a controlled temperature $\left(23 \pm 1^{\circ} \mathrm{C}\right)$ and 12 -h light/dark cycle (dark phase 7:00 p.m. to 7:00 a.m.). Only male mice were used in this study to avoid the effects of the female estrous cycle on behavioral parameters. All animal procedures followed the National Institutes of Health guidelines for the care and use of research rodents, and the Institutional Animal Care and Use Committee reviewed and approved the study protocol.

\section{Chemicals and Reagents}

Heroin was provided by the Anhui provincial public security department (Hefei, China). MDL100907 (Griesler et al., 2019) was purchased from Sigma-Aldrich (Sigma-Aldrich, United States) and was dissolved in dimethyl sulfoxide (DMSO) to prepare different doses (i.e., 0.01, 0.03, 0.1, and $0.3 \mathrm{mg} / \mathrm{kg}$ ) for intraperitoneal (IP) injection. The final concentrations of DMSO of these four doses were $0.6,0.2,0.06$, and $0.02 \%$, respectively.

Naloxone and saline were purchased from The First Affiliated Hospital of Anhui University of Science and Technology (Huainan, China). The time points of MDL100907 treatment were determined based on a previously published report (Wu et al., 2015), and doses were optimized in our laboratory. Naloxone ( $5 \mathrm{mg} / \mathrm{kg}$ ) was administered by IP injection. To minimize background interference of heroin on naloxone binding to various opioid receptors and spontaneous withdrawal precipitation, naloxone was injected $2 \mathrm{~h}$ after heroin was administered (Wu et al., 2015). Naloxone was dissolved in $0.9 \%$ saline solution and administered at a dose of $5 \mathrm{mg} / \mathrm{kg}$. Saline solution was used as a placebo.

For immunoblotting, we used anti-5-HT2AR (ab16028, Abcam, United States) and anti-phospho-ERK1/2 (Cell Signaling Technology, United States) primary antibodies and a horseradish peroxidase (HRP)-conjugated anti-rabbit IgG secondary antibody (SA00001-2, Proteintech, United States). Protein was quantified using a bicinchoninic acid (BCA) assay kit provided by the Beyotime Institute of Biotechnology (Haimen, China).

\section{Basal Locomotor Activity Recording With an Open-Field Test}

The open-field test was conducted as described elsewhere (Pang et al., 2016). Briefly, mice were placed in the center of a white open field with dimensions of $30 \mathrm{~cm} \times 30 \mathrm{~cm} \times 37.5 \mathrm{~cm}$. The movement and activities of the mice were tracked by a video camera equipped with EthoVision-XT-5.1 behavioral tracking software (Noldus Information Technology, Netherlands). The behavioral parameters tested in this study were distance traveled and duration of immobility at a certain coordinate.

Naïve mice were randomly distributed into three groups ( $n=8-18$ per group), which received either placebo (saline), 
M100907 (0.03 mg/kg), or naloxone (5 mg/kg) at designated time points. Behaviors were monitored for $60 \mathrm{~min}$ to evaluate druginduced behavioral changes. The Noldus PhenoTyper system could accurately calculate the horizontal distance traveled, but not fine behaviors. For example, the system could not distinguish between the head and tail when detecting the direction of movement. Behaviors were monitored with video monitoring (e.g., distance traveled) and manual scores (e.g., jumping).

\section{Induction of Heroin Withdrawal}

Heroin was injected subcutaneously twice daily at gradually increasing doses $(5 \mathrm{mg} / \mathrm{kg}$ each time) from 10 to $50 \mathrm{mg} / \mathrm{kg}$ by day 5 . On day 5 , mice were injected with saline or MDL100907 at 8:00 a.m. Thirty minutes later, mice were injected with $50 \mathrm{mg} / \mathrm{kg}$ of heroin or placebo. After $2 \mathrm{~h}$, naloxone was administered to control withdrawal symptoms, including jumping (el-Kadi and Sharif, 1995). The naloxoneprecipitated heroin-withdrawal mouse model is illustrated in Figure 1. Behavioral parameters such as total distance traveled and spontaneous immobility were monitored by video recording. Heroin-withdrawal behaviors after naloxone administration were monitored for $30 \mathrm{~min}$. Withdrawal behaviors included wet dog shakes, body grooming, penile grooming, head shakes, paw licking, jumping (completely in the air), extended posture, rearing, and burrowing (escape digging).

\section{Western Blot}

Mice were euthanized immediately after day 5 of the experiment, and PFC tissue was collected on ice and stored at $-80^{\circ} \mathrm{C}$. PFC tissues were homogenized and lysed in ice-cold $1 \times$ RIPA buffer for protein extraction, followed by centrifugation $\left(4^{\circ} \mathrm{C}\right.$, $10,000 \times g, 10 \mathrm{~min})$. The supernatant containing total protein was transferred to a new Eppendorf tube, and the protein concentration was determined using a BCA protein detection kit. The protein samples were resolved on a $10 \%$ SDS-polyacrylamide gel by electrophoresis and transferred to a polyvinylidene fluoride membrane. The membranes were blocked with non-fat-skimmed milk $(5 \% \mathrm{w} / \mathrm{v})$ and washed with Tris-buffered saline with $0.1 \%$ $\mathrm{v} / \mathrm{v}$ Tween-20, then probed with primary antibody (1:100) overnight at $4^{\circ} \mathrm{C}$, followed by the HRP-conjugated secondary antibody at 1:10,000 dilution for $1.5 \mathrm{~h}$. Protein bands were displayed with enhanced chemiluminescence substrates (Thermo Fisher Scientific Inc.) and captured using a ChemiDoc ${ }^{\mathrm{TM}}$ XRS+ imaging system (BioRad Co., United States). The density of the protein bands was quantified (gray mean value) using ImageJ software (NIH). Density measurements for 5-HT2AR were normalized to the internal control $\beta$-actin (Zhang et al., 2016). There were three independent trials for each group.

\section{Statistical Analysis}

Statistical differences in total distance traveled and duration of immobility were analyzed using two-way repeated-measures ANOVA. All data are expressed as mean \pm SEM. One-way ANOVA and Student's $t$-test were used for statistical analysis. If statistical significance was found $(p<0.05)$, a post hoc Dunnett's test or Bonferroni multiple comparison was conducted.

\section{RESULTS}

\section{MDL100907 Overdosing Impairs Locomotor Activity in Mice}

To observe the effects of MDL100907 on locomotor activity, we first compared the effects of MDL100907 on the distance traveled and immobility duration. MDL100907 treatments at 0.1 and $0.3 \mathrm{mg} / \mathrm{kg}$ doses, but not at 0.01 and $0.03 \mathrm{mg} / \mathrm{kg}$ doses, significantly reduced locomotor activity compared with controls $[F(4,49)=5.457, p=0.0010$; Figure 2A]. MDL100907 treatment had a significant effect not only on the distance traveled $[F(4,36)=6.238, p<0.001]$ and also on the 5-min time bin $[F(11,99)=18.895, p<0.0001]$; however, there was no significant effect on the treatment $\times$ time bin interaction $[F(44,396)=1.344$, $p=0.077$; Figure 2B].

Next, we measured the immobility duration for $1 \mathrm{~h}$ $[F(4,49)=4.667, p=0.0029$, one-way ANOVA post hoc Dunnett's multiple comparisons; Figure 2C]. A two-way repeated-measures ANOVA on immobility, measured in every 5 min, showed no statistically significant effect on immobility duration $[F(4,36)=0.356, p=0.838$; Figure $2 \mathrm{D}]$; however, the duration of MDL100907 treatment had significant effects not only on immobility duration $[F(44,396)=3.480, p<0.0001]$ but also on the time $\times$ treatment interaction $[F(4,36)=0.356$, $p<0.0001]$. Injection of $0.3 \mathrm{mg} / \mathrm{kg}$ MDL100907 did not affect locomotor activity, so $0.03 \mathrm{mg} / \mathrm{kg}$ MDL100907 was administered subcutaneously to heroin-treated mice. We also tested whether MDL100907 affected activity/immobility in the absence of naloxone and found no difference between MDL100907 alone and control (data not shown).

\section{MDL100907 Relieves Naloxone-Induced Precipitated Withdrawal Symptoms in Heroin-Dependent Mice}

Figure 3 shows the frequency of jumping (Figure 3A), rearing (Figure 3B), wet dog shakes (Figure 3C), body grooming (Figure 3D), paw licking (Figure 3E), and extended posture (Figure 3F) was counted for $30 \mathrm{~min}$. Mice showed physical hyperactivities after heroin withdrawal, such as heavily increased rearing and jumping, compared with mice treated with saline and naloxone alone. After heroin withdrawal, MDL100907 significantly suppressed rearing and jumping $(p<0.05)$ but had no effect on the frequency of wet dog shakes, body grooming, and stretched out posture (Figure 3).

\section{MDL100907 Negatively Modulates Distance Moved and Mobility in Naloxone-Precipitated Withdrawal Symptoms}

Heroin dependency was successfully induced after 4.5 days of gradually increasing doses. MDL100907 (0.03 mg/kg) significantly restricted the distance traveled per hour compared with saline treatment $[F(2,37)=30.646, p<0.0001$; Figure 4A; movement track, Figure 4C]. MDL100907 treatment also significantly increased the duration of immobility 


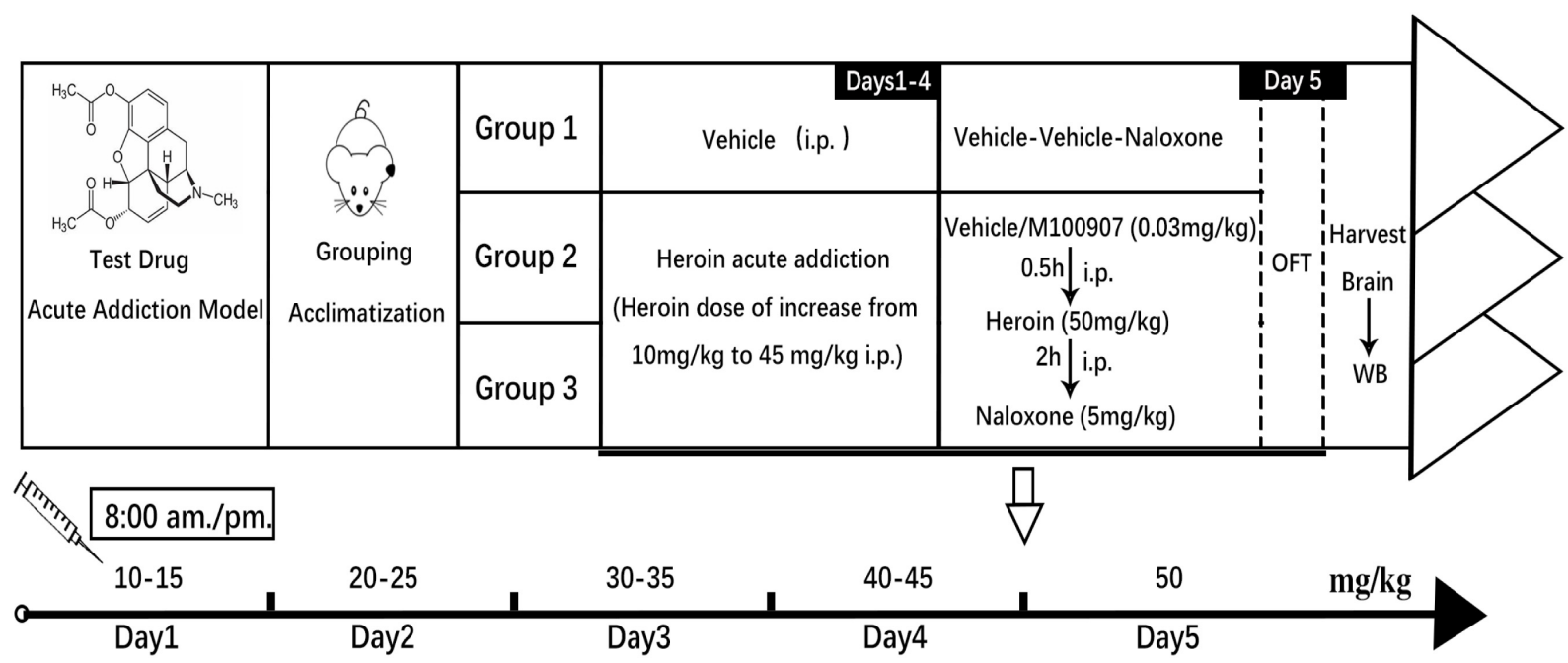

FIGURE 1 | Experimental outline of the animal study. Induction of heroin dependency by administering increasing doses of heroin is shown in the graph. The MDL100907 treatment schedule is also shown.
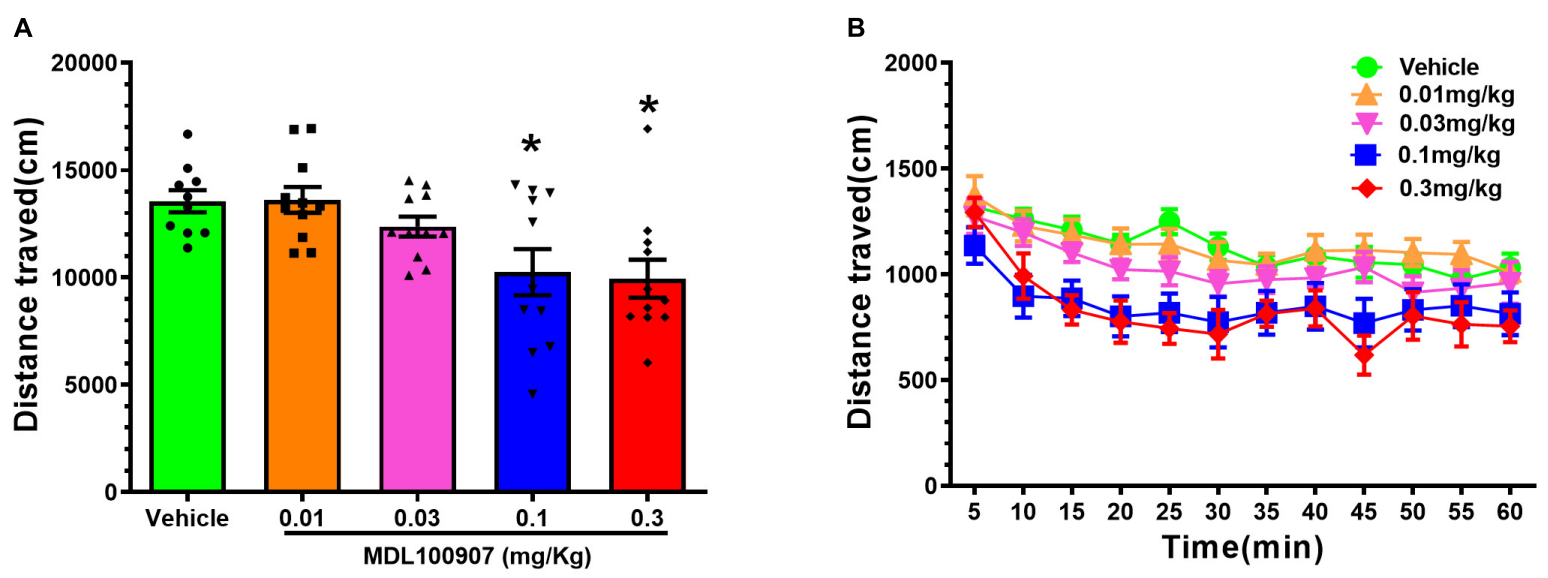

C

D
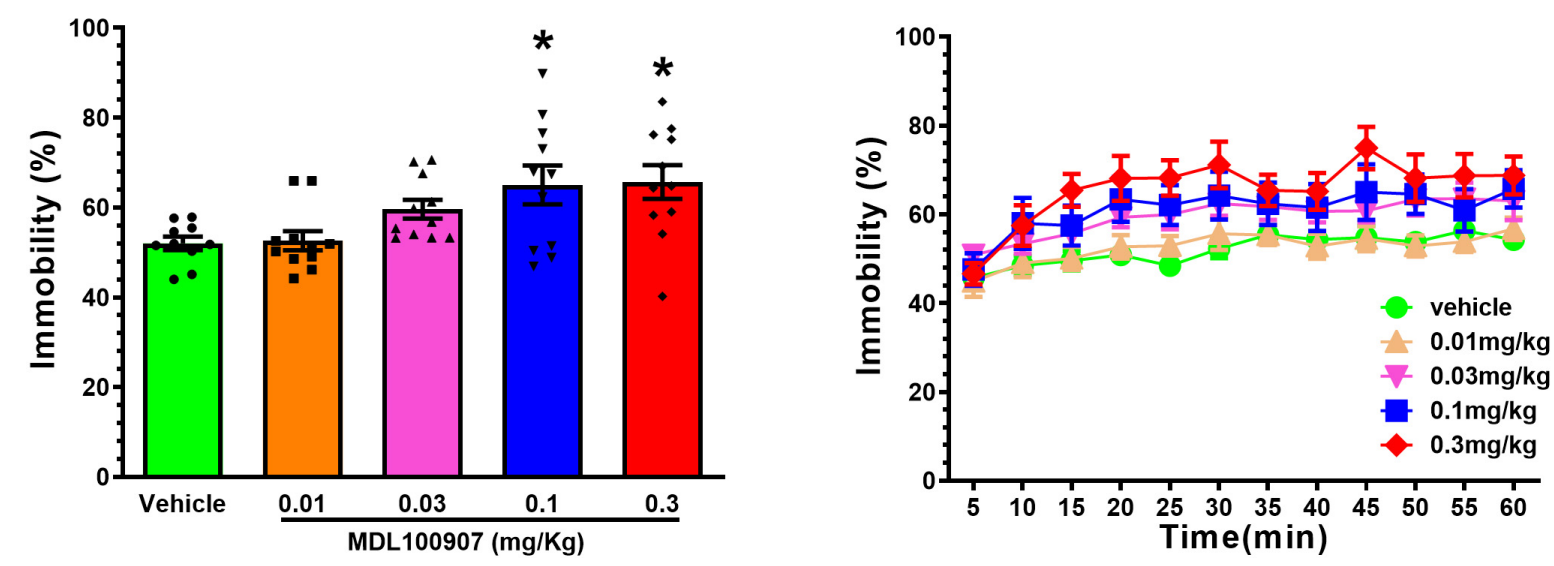

FIGURE 2 | Effects of MDL100907 on locomotor activity. (A) Five groups of naïve mice received one of five MDL100907 doses each (i.e., 0, 0.01, 0.03, 0.1, and $0.3 \mathrm{mg} / \mathrm{kg}$ ). Distance covered in $60 \mathrm{~min}$. (B) Distance covered in a 5-min bin period. (C) Percentage of immobility. (D) Immobility in a 5-min bin period. Data are expressed as mean \pm SEM; $n=8-18$ for each group ${ }^{*} p<0.05$. 

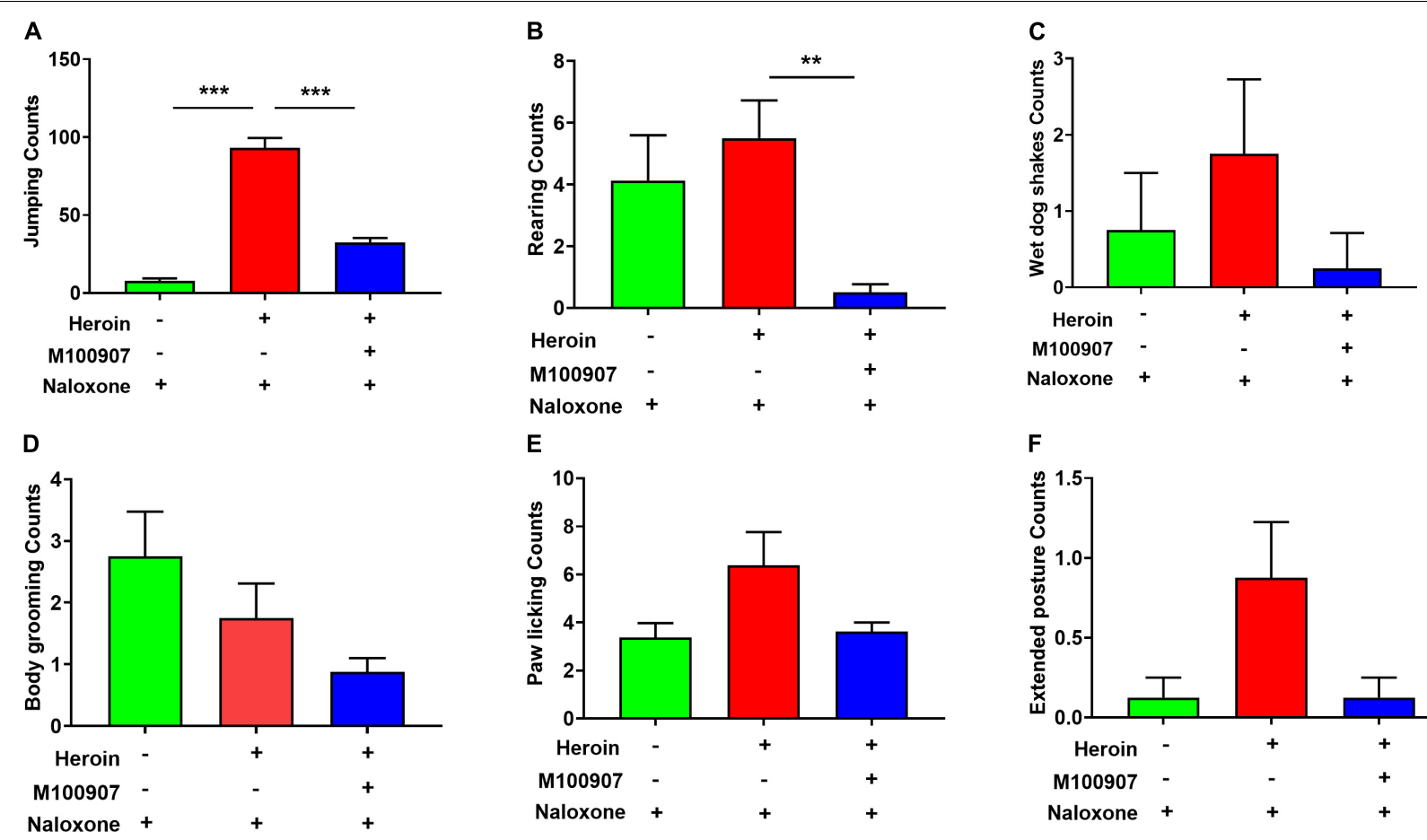

E
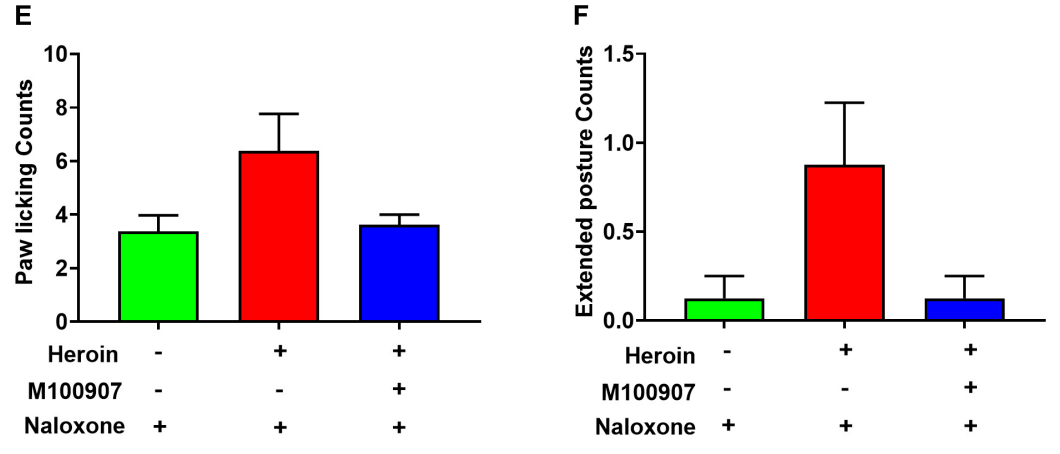

FIGURE 3 | Effects of MDL100907 on naloxone-induced withdrawal symptoms. (A) Jumping. (B) Rearing counting. (C) Wet dog shakes. (D) Body grooming. (E) Paw licking. (F) Extended posture. All behaviors were monitored for $30 \mathrm{~min}$. Data are expressed as mean $\pm \mathrm{SEM}$; $n=8-18$ for each group ** $<<0.01$, ${ }^{* \star *} p<0.001$.

$[F(2,37)=65.70, p<0.01 ;$ Figure $4 \mathrm{~B}]$ after $30 \mathrm{~min}$, but not after $1 \mathrm{~h}$ in naloxone-precipitated heroin-withdrawn mice compared with saline treatment. MDL100907 treatment also reduced the distance moved and increased the duration of immobility $(p<0.05)$ compared with saline treatment.

\section{Heroin Treatment Upregulates 5-Hydroxytryptamine (Serotonin) 2A Receptor Expression and Downregulates ERK Phosphorylation in the Medial Prefrontal Cortex}

Brain tissue was collected from acute heroin-dependent mice $2.5 \mathrm{~h}$ after the last heroin administration, and the levels of 5-HT2AR, ERK, and phosphorylation of extracellular signalregulated kinase ( $\mathrm{p}$-ERK) in the medial prefrontal cortex (mPFC) were quantified by Western blotting. Heroin exposure correlated positively with 5 -HT2AR expression $[t(6)=2.570, p<0.05]$. The p-ERK/ERK ratio in $\mathrm{mPFC}$ tissue $[t(6)=2.88, p<0.05]$ was lower in heroin-treated mice than in saline-treated mice (Figures 5A,B).

\section{DISCUSSION}

People who have experienced heroin dependence are vulnerable to relapses even years into abstinence (Stewart et al., 1984; Lucey et al., 2019). Impulsive reactions to stimuli without regard for the negative consequences can contribute to relapse (Volkow et al., 2019) and are regulated by 5 -HT neurotransmission (Anastasio et al., 2015; Fink et al., 2015). This study explored the influence of 5-HT2ARs on withdrawal symptoms in heroin-treated mice. We report that the 5-HT2AR antagonist MDL100907 attenuates naloxone-precipitated withdrawal symptoms. These findings suggest that 5-HT2ARs regulate behaviors related to heroin dependence and that heroin dependence might be treated by pharmacological activation of 5-HT2ARs.

We found that the 5-HT2AR antagonist MDL100907 alleviates naloxone-induced precipitated withdrawal symptoms in heroinexposed mice. Lower doses of MDL100907 did not affect baseline motor activity, whereas higher doses inhibited heroin-withdrawal symptoms. In line with these findings, another study showed that higher doses of MDL100907 reduce nicotine-withdrawal symptoms in rats (Malin et al., 2019). Previous studies have demonstrated that naloxone-precipitated heroin withdrawal is characterized by jumping, whereas others have suggested that these behaviors are not specific to heroin withdrawal and may be caused by a floor effect (Pang et al., 2016).

The heroin-withdrawal symptoms might be caused by increased long-lasting responses of neurons innervating the nucleus accumbens, dopaminergic neurons in the ventral tegmental area (VTA), and glutamatergic neurons in the PFC and basolateral amygdala (Russo and Nestler, 2013). This suggests that heroin derivatives activate MOR, thereby inducing locomotor hyperactivity and increasing dopaminergic neurotransmission. The VTA-nucleus accumbens circuit is 

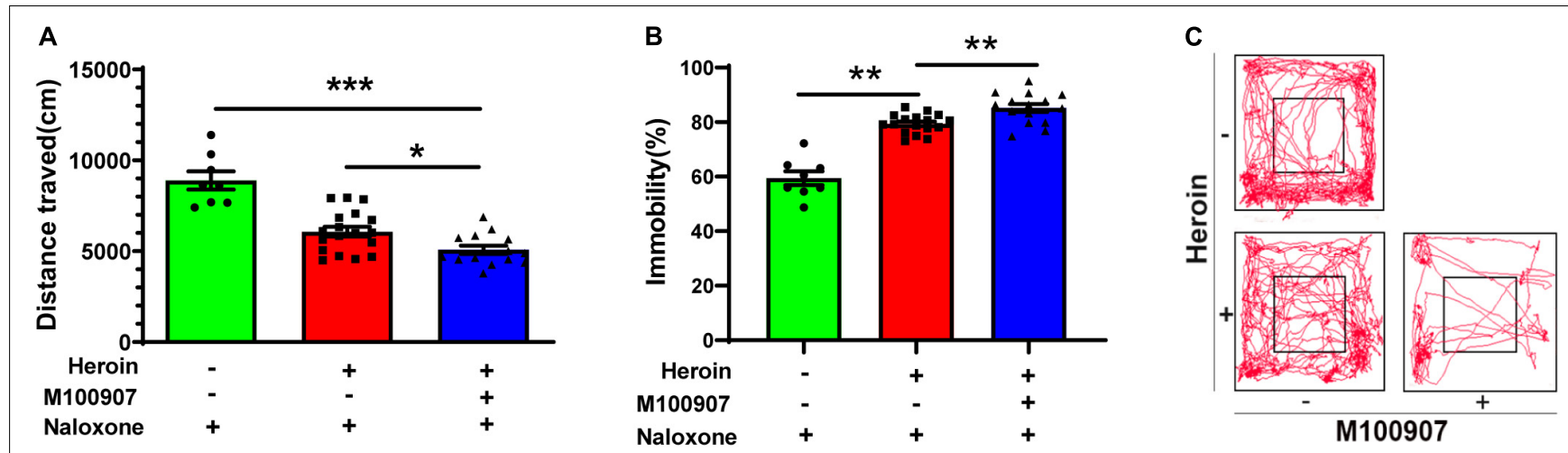

FIGURE 4 | MDL100907 suppresses opioid-withdrawal symptoms. Mice were treated with increasing doses of heroin (10-50 mg/kg) for 4.5 days to develop heroin dependency. (A,B) MDL100907 significantly reduced the distance traveled and significantly increased immobility. Plot tracking of the open-field test is shown.

(C) MDL100907 reduced hyperactive walking activity in heroin-exposed mice treated with naloxone, but not in heroin-exposed mice treated with saline. Data are expressed as mean $\pm \mathrm{SEM} ; n(\mathrm{C})=8-18 ;{ }^{*} p<0.05 ;{ }^{\star *} p<0.01 ;{ }^{* \star *} p<0.001$ vs. saline.
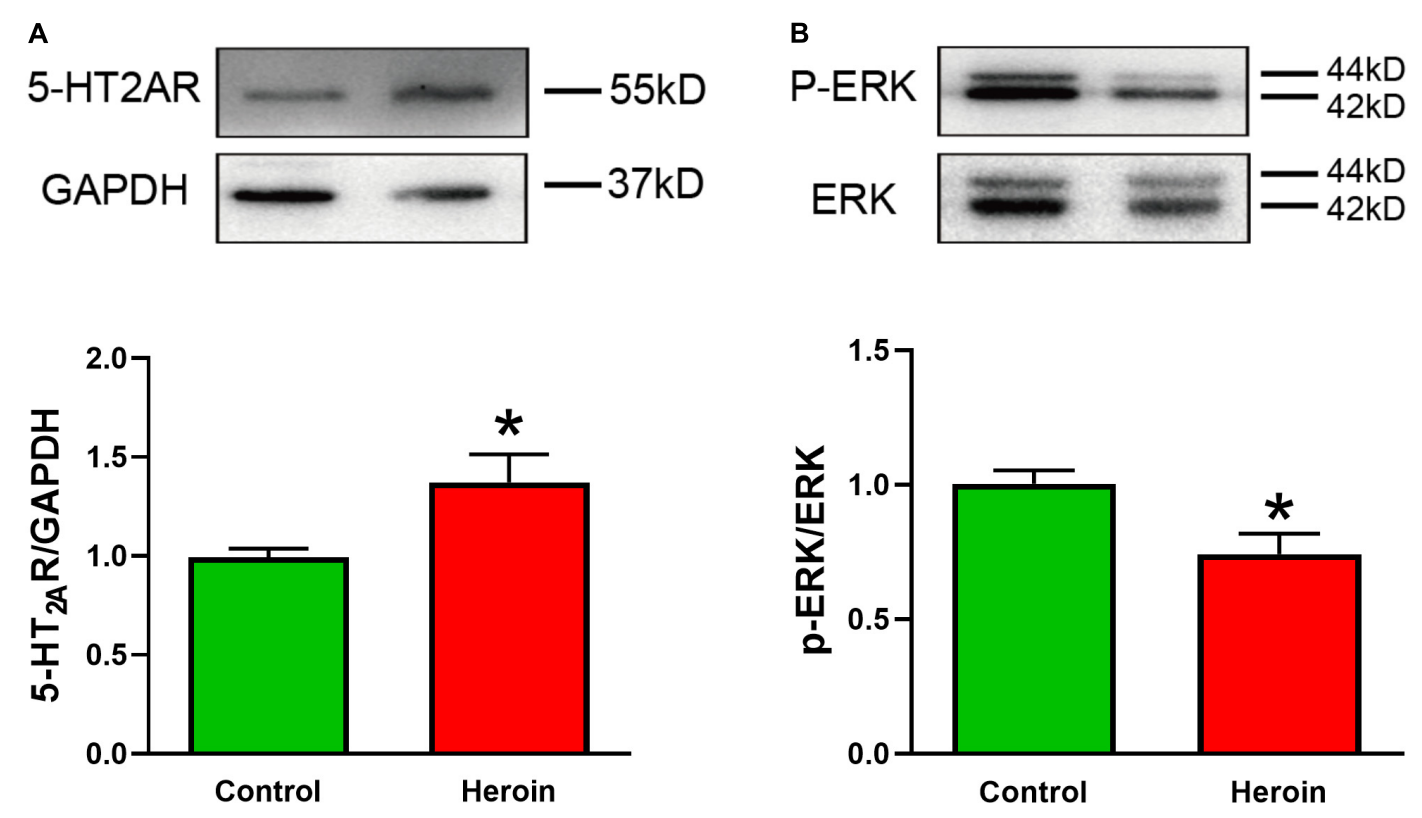

FIGURE 5 | Acute heroin exposure is associated with increased 5-HT2AR expression and decreased p-ERK expression in the PFC. Mice were injected with increasing concentrations of heroin for 5 days to develop heroin dependency, and PFC tissue was collected $2.5 \mathrm{~h}$ after the last shot of heroin. (A,B) Acute heroin treatment increased 5-HT2AR protein levels and decreased the $p$-ERK/ERK ratio in PFC tissue. Data are expressed as mean \pm SEM; $n=4$ per group; ${ }^{*} p<0.05$ vs. saline group.

critical for reward recognition and includes the mPFC, amygdala, hippocampus, and other regions regulated by dopaminergic neurons. Previous studies have revealed that dopaminergic neurons in the nucleus accumbens can secret glutamate and $\gamma$-aminobutyric acid (GABA), which may contribute to dependence on opioids (Hnasko et al., 2012; Tritsch et al., 2012). 5-HT2ARs are widely distributed in intermediate inhibitory neurons, major VTA neurons, dorsomedial PFC neurons, and BLA neurons (Kreek et al., 2012). The 5-HT2AR is expressed in GABA-ergic neurons in the midbrain, substantia nigra, and VTA, but not in dopaminergic neurons (Kuehn, 2013). Furthermore, the 5-HT2AR antagonist MDL100907 reduces the firing rate of dopaminergic neurons in the mesolimbic system (Lucey et al., 2019). These results suggest that MDL100907-mediated blocking of 5-HT2ARs may inhibit dopamine neurotransmission, which may inhibit heroin-withdrawal symptoms in mice. Neuronal excitation is crucial to heroin withdrawal and may be blocked by MDL100907 treatment. Further experiments are warranted to delineate the underlying mechanisms.

Immunoblot analysis revealed that 5-HT2AR expression was upregulated in PFC tissue from heroin-dependent mice. The PFC is a key brain region associated with opioid addictive behavior, so the increased 5-HT2AR expression we observed suggests a crucial link to neural adaptation upon heroin 
exposure. However, the functional significance of 5-HT2AR overexpression in heroin addiction remains elusive. Elucidating the subcellular distribution and receptor signal transduction of 5-HT2AR will help understand the regulatory mechanisms of heroin dependence. Interestingly, we observed reduced ERK phosphorylation in PFC tissue from heroin-dependent mice, although 5-HT2AR activation upregulates p-ERK1/2 expression. Heroin triggers multiple cellular signaling cascades and, together with its metabolites, can have diverse effects in different brain regions, neural networks, and cell types. This variability might explain the inconsistency between the heroin-mediated increase in 5-HT2AR expression and reduced p-ERK accumulation we observed. It was recently reported that morphine also downregulates $\mathrm{p}$-ERK/ERK. This effect was induced by the D1RERK-CREB pathway in the mPFC, and the D1R antagonist SCH-23390 reversed morphine-induced attention dysfunction and morphine-withdrawal symptoms in mice (Yin et al., 2021).

The 5-HT2AR-mediated heroin withdrawal may involve dopamine neurotransmission. 5-HT2ARs control dopamine outflow to augment dopamine synthesis and excitation (Schmidt et al., 1992; Lucas and Spampinato, 2000; Porras et al., 2002; Alex and Pehek, 2007). However, selective blockade of 5-HT2ARs by SR46349B did not affect the cocaine-induced increase in dopamine outflow in the nucleus accumbens and striatum (Auclair et al., 2004). Furthermore, MDL100907 did not affect basal and cocaine-augmented dopamine outflow into the mPFC (Bonaccorso et al., 2002; Fletcher et al., 2002; Li et al., 2005; Berg et al., 2008), whereas coadministration of MDL100907 and the 5-HT2CR antagonist lorcaserin suppressed cocaineseeking behavior (Anastasio et al., 2020). 5-HT receptors control ascending dopamine pathway activity and the neurochemical and behavioral responses to cocaine (Alex and Pehek, 2007; Berg et al., 2008; Filip et al., 2012; Devroye et al., 2013; Howell and Cunningham, 2015; Sholler et al., 2019). However, their impact on cocaine-mediated increases in dopamine production in the $\mathrm{mPFC}$ remains unclear. Dopaminergic signaling also contributes to opioid addiction by modulating the hypothalamic-pituitaryadrenal (HPA) axis. The relationship between cocaine use, the

\section{REFERENCES}

Alex, K. D., and Pehek, E. A. (2007). Pharmacologic mechanisms of serotonergic regulation of dopamine neurotransmission. Pharmacol. Ther. 113, 296-320. doi: 10.1016/j.pharmthera.2006.08.004

Anastasio, N. C., Sholler, D. J., Fox, R. G., Stutz, S. J., Merritt, C. R., Bjork, J. M., et al. (2020). Suppression of cocaine relapse-like behaviors upon pimavanserin and lorcaserin co-administration. Neuropharmacology 168:108009. doi: 10.1016/j. neuropharm.2020.108009

Anastasio, N. C., Stutz, S. J., Fink, L. H., Swinford-Jackson, S. E., Sears, R. M., Dileone, R. J., et al. (2015). Serotonin (5-HT) 5-HT2A receptor (5HT2AR):5-HT2CR imbalance in medial prefrontal cortex associates with motor impulsivity. ACS Chem. Neurosci. 6, 1248-1258. doi: 10.1021/acschemneuro. 5b00094

Auclair, A., Drouin, C., Cotecchia, S., Glowinski, J., and Tassin, J. P. (2004). 5-HT2A and alphalb-adrenergic receptors entirely mediate dopamine release, locomotor response and behavioural sensitization to opiates and psychostimulants. Eur. J. Neurosci. 20, 3073-3084. doi: 10.1111/j.1460-9568. 2004.03805.x
HPA axis, and opioid use is well-established (Nava et al., 2006; Picetti et al., 2013; Walter et al., 2013), and it will be interesting to elucidate the role of the HPA axis on heroin dependence in a future study.

Taken together, our data have shown that naloxone-induced heroin-withdrawal symptoms can be attenuated by MDL100907. Acute heroin addiction increased 5-HT2AR expression in the PFC, suggesting that 5-HT2AR might be an efficient therapeutic target for treating heroin use disorders.

\section{DATA AVAILABILITY STATEMENT}

The raw data supporting the conclusions of this article will be made available by the authors, without undue reservation.

\section{ETHICS STATEMENT}

The animal study was reviewed and approved by the Institutional Animal Care and Use Committee (IACUC).

\section{AUTHOR CONTRIBUTIONS}

GP and XT conceived and designed the study. BL, JJ, LZ, QS, $\mathrm{JL}$, and YL conducted the experiments, collected the data, and prepared the manuscript. All authors contributed to the article and approved the submitted version.

\section{FUNDING}

The funding supports for this project was obtained from the Anhui Provincial Natural Science Foundation (1808085MH247), the Chinese National Natural Science Foundation (81471161), and the Chinese National Student's Innovation and Entrepreneurship Training Program (202010361118).

Ballard, C., Banister, C., Khan, Z., Cummings, J., Demos, G., Coate, B., et al. (2018). Evaluation of the safety, tolerability, and efficacy of pimavanserin versus placebo in patients with Alzheimer's disease psychosis: a phase 2, randomised, placebocontrolled, double-blind study. Lancet Neurol. 17, 213-222. doi: 10.1016/S14744422(18)30039-5

Banerjee, G., Edelman, E. J., Barry, D. T., Crystal, S., Gordon, K. S., Gordon, A. J., et al. (2019). High-dose prescribed opioids are associated with increased risk of heroin use among United States military veterans. Pain 160, 2126-2135. doi: 10.1097/j.pain.000000000000 1606

Berg, K. A., Harvey, J. A., Spampinato, U., and Clarke, W. P. (2008). Physiological and therapeutic relevance of constitutive activity of 5-HT 2A and 5-HT 2C receptors for the treatment of depression. Prog. Brain Res. 172, 287-305. doi: 10.1016/S0079-6123(08)00914-X

Bonaccorso, S., Meltzer, H. Y., Li, Z., Dai, J., Alboszta, A. R., and Ichikawa, J. (2002). SR46349-B, a 5-HT(2A/2C) receptor antagonist, potentiates haloperidolinduced dopamine release in rat medial prefrontal cortex and nucleus accumbens. Neuropsychopharmacology 27, 430-441. doi: 10.1016/S0893$133 \mathrm{X}(02) 00311-1$ 
Chen, Y. N., Wang, J., Zhang, J., Li, S. J., He, L., Shao, D. D., et al. (2013). Effect of thimerosal on the neurodevelopment of premature rats. World J. Pediatr. 9, 356-360. doi: 10.1007/s12519-013-0443-z

Cummings, J., Isaacson, S., Mills, R., Williams, H., Chi-Burris, K., Corbett, A., et al. (2014). Pimavanserin for patients with Parkinson's disease psychosis: a randomised, placebo-controlled phase 3 trial. Lancet 383, 533-540. doi: 10. 1016/S0140-6736(13)62106-6

Cunningham, K. A., Anastasio, N. C., Fox, R. G., Stutz, S. J., Bubar, M. J., Swinford, S. E., et al. (2013). Synergism between a serotonin 5-HT2A receptor (5-HT2AR) antagonist and 5-HT2CR agonist suggests new pharmacotherapeutics for cocaine addiction. ACS Chem. Neurosci. 4, 110-121. doi: 10.1021/cn300072u

Dart, R. C., Severtson, S. G., and Bucher-Bartelson, B. (2015). Trends in opioid analgesic abuse and mortality in the United States. N. Engl. J. Med. 372, 1573-1574.

Devroye, C., Filip, M., Przegalinski, E., Mccreary, A. C., and Spampinato, U. (2013). Serotonin2C receptors and drug addiction: focus on cocaine. Exp. Brain Res. 230, 537-545. doi: 10.1007/s00221-013-3593-2

Dong, H., Hayashi, K., Singer, J., Milloy, M. J., Debeck, K., Wood, E., et al. (2019). Trajectories of injection drug use among people who use drugs in Vancouver, Canada, 1996-2017: growth mixture modeling using data from prospective cohort studies. Addiction 114, 2173-2186. doi: 10.1111/add.14756

El Mansari, M., and Blier, P. (2006). Mechanisms of action of current and potential pharmacotherapies of obsessive-compulsive disorder. Prog. Neuropsychopharmacol. Biol. Psychiatry 30, 362-373. doi: 10.1016/j.pnpbp. 2005.11.005

el-Kadi, A. O., and Sharif, S. I. (1995). The role of 5-HT in the expression of morphine withdrawal in mice. Life Sci. 57, 511-516. doi: 10.1016/0024-3205(95) 00284-d

Felsing, D. E., Anastasio, N. C., Miszkiel, J. M., Gilbertson, S. R., Allen, J. A., and Cunningham, K. A. (2018). Biophysical validation of serotonin 5-HT2A and 5HT2C receptor interaction. PLoS One 13:e0203137. doi: 10.1371/journal.pone. 0203137

Filip, M., Spampinato, U., Mccreary, A. C., and Przegalinski, E. (2012). Pharmacological and genetic interventions in serotonin $(5-\mathrm{HT})(2 \mathrm{C})$ receptors to alter drug abuse and dependence processes. Brain Res. 1476, 132-153. doi: 10.1016/j.brainres.2012.03.035

Fink, L. H., Anastasio, N. C., Fox, R. G., Rice, K. C., Moeller, F. G., and Cunningham, K. A. (2015). Individual differences in impulsive action reflect variation in the cortical serotonin 5-HT2A receptor system. Neuropsychopharmacology 40, 1957-1968. doi: 10.1038/npp.2015.46

Fletcher, P. J., Grottick, A. J., and Higgins, G. A. (2002). Differential effects of the 5-HT(2A) receptor antagonist M100907 and the 5-HT(2C) receptor antagonist SB242084 on cocaine-induced locomotor activity, cocaine self-administration and cocaine-induced reinstatement of responding. Neuropsychopharmacology 27, 576-586. doi: 10.1016/S0893-133X(02)00342-1

Girgis, R. R., Forbes, A., Abi-Dargham, A., and Slifstein, M. (2020). A positron emission tomography occupancy study of brexpiprazole at dopamine D2 and D3 and serotonin 5-HT1A and 5-HT2A receptors, and serotonin reuptake transporters in subjects with schizophrenia. Neuropsychopharmacology 45, 786792. doi: 10.1038/s41386-019-0590-6

Gourley, S. L., and Taylor, J. R. (2016). Going and stopping: dichotomies in behavioral control by the prefrontal cortex. Nat. Neurosci. 19, 656-664. doi: 10.1038/nn.4275

Granier, S., Manglik, A., Kruse, A. C., Kobilka, T. S., Thian, F. S., Weis, W. I., et al. (2012). Structure of the delta-opioid receptor bound to naltrindole. Nature 485, 400-404. doi: 10.1038/nature11111

Griesler, P. C., Hu, M. C., Wall, M. M., and Kandel, D. B. (2019). Medical use and misuse of prescription opioids in the US adult population: 2016-2017. Am. J. Public Health 109, 1258-1265. doi: 10.2105/AJPH.2019.305162

Grischott, T., Falcato, L., Senn, O., Puhan, M. A., and Bruggmann, P. (2019). Chronic obstructive pulmonary disease (COPD) among opioid-dependent patients in agonist treatment. A diagnostic study. Addiction 114, 868-876. doi: 10.1111/add.14559

Hnasko, T. S., Hjelmstad, G. O., Fields, H. L., and Edwards, R. H. (2012). Ventral tegmental area glutamate neurons: electrophysiological properties and projections. J. Neurosci. 32, 15076-15085. doi: 10.1523/JNEUROSCI.3128-12. 2012
Howell, L. L., and Cunningham, K. A. (2015). Serotonin 5-HT2 receptor interactions with dopamine function: implications for therapeutics in cocaine use disorder. Pharmacol. Rev. 67, 176-197. doi: 10.1124/pr.114.009514

Inturrisi, C. E., Schultz, M., Shin, S., Umans, J. G., Angel, L., and Simon, E. J. (1983). Evidence from opiate binding studies that heroin acts through its metabolites. Life Sci. 33(Suppl. 1), 773-776. doi: 10.1016/0024-3205(83)90616-1

Jalal, H., Buchanich, J. M., Roberts, M. S., Balmert, L. C., Zhang, K., and Burke, D. S. (2018). Changing dynamics of the drug overdose epidemic in the United States from 1979 through 2016. Science 361:eaau1184. doi: 10.1126/science.aau1184

Johnson, S. W., and North, R. A. (1992). Opioids excite dopamine neurons by hyperpolarization of local interneurons. J. Neurosci. 12, 483-488. doi: 10.1523/ JNEUROSCI.12-02-00483.1992

Jones, C. M., Underwood, N., and Compton, W. M. (2020). Increases in methamphetamine use among heroin treatment admissions in the United States, 2008-17. Addiction 115, 347-353. doi: 10.1111/add.14812

Kelley-Quon, L. I., Cho, J., Strong, D. R., Miech, R. A., Barrington-Trimis, J. L., Kechter, A., et al. (2019). Association of nonmedical prescription opioid use with subsequent heroin use initiation in adolescents. JAMA Pediatr. 173:e191750. doi: 10.1001/jamapediatrics.2019.1750

Kreek, M. J., Levran, O., Reed, B., Schlussman, S. D., Zhou, Y., and Butelman, E. R. (2012). Opiate addiction and cocaine addiction: underlying molecular neurobiology and genetics. J. Clin. Invest. 122, 3387-3393. doi: 10.1172/ JCI60390

Kuehn, B. M. (2013). SAMHSA: pain medication abuse a common path to heroin: experts say this pattern likely driving heroin resurgence. JAMA 310, 1433-1434. doi: 10.1001/jama.2013.278861

Li, Z., Ichikawa, J., Huang, M., Prus, A. J., Dai, J., and Meltzer, H. Y. (2005). ACP-103, a 5-HT2A/2C inverse agonist, potentiates haloperidol-induced dopamine release in rat medial prefrontal cortex and nucleus accumbens. Psychopharmacology 183, 144-153. doi: 10.1007/s00213-005-0170-9

Lucas, G., and Spampinato, U. (2000). Role of striatal serotonin2A and serotonin2C receptor subtypes in the control of in vivo dopamine outflow in the rat striatum. J. Neurochem. 74, 693-701. doi: 10.1046/j.1471-4159.2000.740693.x

Lucey, C. R., Jones, L., and Eastburn, A. (2019). A lethal hidden curriculum - death of a medical student from opioid use disorder. N. Engl. J. Med. 381, 793-795. doi: 10.1056/NEJMp1901537

Malin, D., Henceroth, M., Rao, G. S., Campbell, J., Ma, J. N., Tsai, P. H., et al. (2019). Inverse agonists of the 5-HT2A receptor reduce nicotine withdrawal signs in rats. Neurosci. Lett. 713:134524. doi: 10.1016/j.neulet.2019.134524

Mora, S., Merchan, A., Vilchez, O., Aznar, S., Klein, A. B., Ultved, L., et al. (2018). Reduced cortical serotonin 5-HT2A receptor binding and glutamate activity in high compulsive drinker rats. Neuropharmacology 143, 10-19. doi: 10.1016/j. neuropharm.2018.09.004

Moreno-Rius, J. (2019). Opioid addiction and the cerebellum. Neurosci. Biobehav. Rev. 107, 238-251. doi: 10.1016/j.neubiorev.2019.09.015

Morris, A. (2017). Obesity: 5-HT2A in GLP1-mediated weight loss. Nat. Rev. Endocrinol. 13:127. doi: 10.1038/nrendo.2017.8

Nava, F., Caldiroli, E., Premi, S., and Lucchini, A. (2006). Relationship between plasma cortisol levels, withdrawal symptoms and craving in abstinent and treated heroin addicts. J. Addict. Dis. 25, 9-16. doi: 10.1300/J069v25n02_02

Nightingale, R., Mortimer, K., Giorgi, E., Walker, P. P., Stolbrink, M., Byrne, T., et al. (2020). Screening heroin smokers attending community drug clinics for change in lung function: a cohort study. Chest 157, 558-565. doi: 10.1016/j. chest.2019.11.006

Odabas-Geldiay, M., Shields, H., Berro, L. F., Rice, K. C., and Howell, L. L. (2019). Effects of acute treatments with the serotonin 2A antagonist M100907 alone or in combination with the serotonin 2C agonist WAY163909 on methamphetamine self-administration in rhesus monkeys. Drug Alcohol. Depend. 194, 252-256. doi: 10.1016/j.drugalcdep.2018.10.018

Odagaki, Y., Kinoshita, M., Meana, J. J., Callado, L. F., and Garcia-Sevilla, J. A. (2021a). 5-HT2A receptor- and M1 muscarinic acetylcholine receptor-mediated activation of Galphaq/11 in postmortem dorsolateral prefrontal cortex of opiate addicts. Pharmacol. Rep. 73, 1155-1163. doi: 10.1007/s43440-021-00248-w

Odagaki, Y., Kinoshita, M., Meana, J. J., Callado, L. F., and Garcia-Sevilla, J. A. (2021b). 5-HT2A receptor-mediated Galphaq/11 activation in psychiatric disorders: a postmortem study. World J. Biol. Psychiatry 22, 505-515. doi: 10. $1080 / 15622975.2020 .1839967$ 
Ohno, Y., Shimizu, S., Tokudome, K., Kunisawa, N., and Sasa, M. (2015). New insight into the therapeutic role of the serotonergic system in Parkinson's disease. Prog. Neurobiol. 134, 104-121. doi: 10.1016/j.pneurobio.2015. 09.005

Pang, G., Wu, X., Tao, X., Mao, R., Liu, X., Zhang, Y. M., et al. (2016). Blockade of serotonin 5-HT2A receptors suppresses behavioral sensitization and naloxone-precipitated withdrawal symptoms in morphine-treated mice. Front. Pharmacol. 7:514. doi: 10.3389/fphar.2016.00514

Perez-Aguilar, J. M., Shan, J., Levine, M. V., Khelashvili, G., and Weinstein, H. (2014). A functional selectivity mechanism at the serotonin-2A GPCR involves ligand-dependent conformations of intracellular loop 2. J. Am. Chem. Soc. 136, 16044-16054. doi: 10.1021/ja508394x

Picetti, R., Schlussman, S. D., Zhou, Y., Ray, B., Ducat, E., Yuferov, V., et al. (2013). Addictions and stress: clues for cocaine pharmacotherapies. Curr. Pharm. Des. 19, 7065-7080. doi: 10.2174/13816128113199990610

Pogorelov, V. M., Rodriguiz, R. M., Cheng, J., Huang, M., Schmerberg, C. M., Meltzer, H. Y., et al. (2017). 5-HT2C agonists modulate schizophrenia-like behaviors in mice. Neuropsychopharmacology 42, 2163-2177. doi: 10.1038/npp. 2017.52

Porras, G., Di Matteo, V., Fracasso, C., Lucas, G., De Deurwaerdere, P., Caccia, S., et al. (2002). 5-HT2A and 5-HT2C/2B receptor subtypes modulate dopamine release induced in vivo by amphetamine and morphine in both the rat nucleus accumbens and striatum. Neuropsychopharmacology 26, 311-324. doi: 10.1016/ S0893-133X(01)00333-5

Prabhakaran, J., Underwood, M. D., Kumar, J. S., Simpson, N. R., Kassir, S. A., Bakalian, M. J., et al. (2015). Synthesis and in vitro evaluation of [18F]FECIMBI-36: a potential agonist PET ligand for 5-HT2A/2C receptors. Bioorg. Med. Chem. Lett. 25, 3933-3936. doi: 10.1016/j.bmcl.2015.07.034

Price, A. E., Sholler, D. J., Stutz, S. J., Anastasio, N. C., and Cunningham, K. A. (2019). Endogenous serotonin 5-HT2A and 5-HT2C receptors associate in the medial prefrontal cortex. ACS Chem. Neurosci. 10, 3241-3248. doi: 10.1021/ acschemneuro.8b00669

Reardon, S. (2019). The US opioid epidemic is driving a spike in infectious diseases. Nature 571, 15-16. doi: 10.1038/d41586-019-02019-3

Russo, S. J., and Nestler, E. J. (2013). The brain reward circuitry in mood disorders. Nat. Rev. Neurosci. 14, 609-625. doi: 10.1038/nrn3381

Schmidt, C. J., Fadayel, G. M., Sullivan, C. K., and Taylor, V. L. (1992). 5-HT2 receptors exert a state-dependent regulation of dopaminergic function: studies with MDL 100,907 and the amphetamine analogue, 3,4-methylenedioxymethamphetamine. Eur. J. Pharmacol. 223, 65-74. doi: 10.1016/0014-2999(92)90819-p

Sholler, D. J., Stutz, S. J., Fox, R. G., Boone, E. L., Wang, Q., Rice, K. C., et al. (2019). The 5-HT2A receptor (5-HT2AR) regulates impulsive action and cocaine cue reactivity in male sprague-dawley rats. J. Pharmacol. Exp. Ther. 368, 41-49. doi: 10.1124/jpet.118.251199

Simpson, H. B., Slifstein, M., Bender, J. Jr., Xu, X., Hackett, E., Maher, M. J., et al. (2011). Serotonin 2A receptors in obsessive-compulsive disorder: a positron emission tomography study with [11C]MDL 100907. Biol. Psychiatry 70, 897904. doi: 10.1016/j.biopsych.2011.06.023

Sinopoli, V. M., Burton, C. L., Kronenberg, S., and Arnold, P. D. (2017). A review of the role of serotonin system genes in obsessive-compulsive disorder. Neurosci. Biobehav. Rev. 80, 372-381. doi: 10.1016/j.neubiorev.2017.05.029

Steeves, T. D., and Fox, S. H. (2008). Neurobiological basis of serotonin-dopamine antagonists in the treatment of Gilles de la Tourette syndrome. Prog. Brain Res. 172, 495-513. doi: 10.1016/S0079-6123(08)00924-2
Stewart, J., De Wit, H., and Eikelboom, R. (1984). Role of unconditioned and conditioned drug effects in the self-administration of opiates and stimulants. Psychol. Rev. 91, 251-268. doi: 10.1037/0033-295x.91.2.251

Tashkin, D. P. (2019). Heroin smoking and COPD: a case for targeted screening spirometry. Chest 155, 247-248. doi: 10.1016/j.chest.2018.08.1039

Teegarden, B. R., Al Shamma, H., and Xiong, Y. (2008). 5-HT(2A) inverse-agonists for the treatment of insomnia. Curr. Top. Med. Chem. 8, 969-976. doi: 10.2174/ 156802608784936700

Tritsch, N. X., Ding, J. B., and Sabatini, B. L. (2012). Dopaminergic neurons inhibit striatal output through non-canonical release of GABA. Nature 490, 262-266. doi: $10.1038 /$ nature 11466

Underwood, M. D., Kassir, S. A., Bakalian, M. J., Galfalvy, H., Dwork, A. J., Mann, J. J., et al. (2018). Serotonin receptors and suicide, major depression, alcohol use disorder and reported early life adversity. Transl. Psychiatry 8:279. doi: 10.1038/s41398-018-0309-1

Volkow, N. D., Jones, E. B., Einstein, E. B., and Wargo, E. M. (2019). Prevention and treatment of opioid misuse and addiction: a review. JAMA Psychiatry 76, 208-216. doi: 10.1001/jamapsychiatry.2018.3126

Walter, M., Gerber, H., Kuhl, H. C., Schmid, O., Joechle, W., Lanz, C., et al. (2013). Acute effects of intravenous heroin on the hypothalamic-pituitaryadrenal axis response: a controlled trial. J. Clin. Psychopharmacol. 33, 193-198. doi: 10.1097/JCP.0b013e31828393cb

Weisstaub, N. V., Zhou, M., Lira, A., Lambe, E., Gonzalez-Maeso, J., Hornung, J. P., et al. (2006). Cortical 5-HT2A receptor signaling modulates anxiety-like behaviors in mice. Science 313, 536-540. doi: 10.1126/science.1123432

Wu, X., Pang, G., Zhang, Y. M., Li, G., Xu, S., Dong, L., et al. (2015). Activation of serotonin $5-\mathrm{HT}(2 \mathrm{C})$ receptor suppresses behavioral sensitization and naloxoneprecipitated withdrawal symptoms in heroin-treated mice. Neurosci. Lett. 607, 23-28. doi: 10.1016/j.neulet.2015.09.013

Yin, F., Zhang, J., Lu, Y., Zhang, Y., Liu, J., Deji, C., et al. (2021). Modafinil rescues repeated morphine-induced synaptic and behavioural impairments via activation of D1R-ERK-CREB pathway in medial prefrontal cortex. Addict. Biol. 27:e13103. doi: 10.1111/adb.13103

Zhang, G., Wu, X., Zhang, Y. M., Liu, H., Jiang, Q., Pang, G., et al. (2016). Activation of serotonin 5-HT(2C) receptor suppresses behavioral sensitization and naloxone-precipitated withdrawal symptoms in morphine-dependent mice. Neuropharmacology 101, 246-254. doi: 10.1016/j.neuropharm.2015.09. 031

Conflict of Interest: The authors declare that the research was conducted in the absence of any commercial or financial relationships that could be construed as a potential conflict of interest.

Publisher's Note: All claims expressed in this article are solely those of the authors and do not necessarily represent those of their affiliated organizations, or those of the publisher, the editors and the reviewers. Any product that may be evaluated in this article, or claim that may be made by its manufacturer, is not guaranteed or endorsed by the publisher.

Copyright (c) 2022 Li, Jiang, Zhou, Tao, Sun, Liu, Liu and Pang. This is an open-access article distributed under the terms of the Creative Commons Attribution License (CC BY). The use, distribution or reproduction in other forums is permitted, provided the original author(s) and the copyright owner(s) are credited and that the original publication in this journal is cited, in accordance with accepted academic practice. No use, distribution or reproduction is permitted which does not comply with these terms. 